\title{
Differential diagnostic challenges during the Covid-19 pandemic for pediatricians in an Eastern European country where newborn screening of cystic fibrosis is not available: A case report
}

\author{
Szofia Hajósi-Kalcakosz ${ }^{1}$, Borbála Zsigmond ${ }^{1}$, Andrea Párniczky ${ }^{1}$, and Reka Bodnar ${ }^{1}$ \\ ${ }^{1}$ Heim Pál Gyermekkórház
}

November 18, 2020

\begin{abstract}
Newborn screening (NBS) of cystic fibrosis (CF) is not available currently in Hungary. Pediatricians should be able to recognize the illness based on the symptoms alone. Lack of NBS causes differential diagnostic challenges for physicians and delayed diagnosis of CF. We present a case of a two-year-old girl who was transferred to our hospital as a suspected Covid-19 patient with one week history of fever and coughing in March 2020. As Covid-19 was excluded, the severity of the clinical picture pointed towards an acute exacerbation of an underlying chronic condition. Her symptoms such as tachypnea, wheezing, lung crackles, hepatomegaly and clubbing of the fingers were all consistent with undiagnosed CF. In the end, sweat chloride level and genetic test verified the diagnosis. This case emphasizes the need of NBS in Hungary.
\end{abstract}

Differential diagnostic challenges during the Covid-19 pandemic for pediatricians in an Eastern European country where newborn screening of cystic fibrosis is not available: A case report

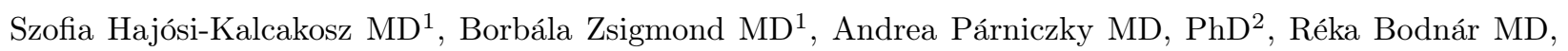
$\mathrm{PhD}^{2}$

${ }^{1}$ Heim Pál Children's Hospital, Department of Infectious Diseases, Budapest, Hungary

${ }^{2}$ Heim Pál Children's Hospital, Cystic Fibrosis Outpatient Care Unit, Budapest, Hungary

Corresponding author e-mail address: rekabodnar@ymail.com

postal address: Heim Pál Children’s Hospital, 1089, Üllói Street 86., Budapest, Hungary

\section{Abstract}

Newborn screening (NBS) of cystic fibrosis (CF) is not available currently in Hungary. Pediatricians should be able to recognize the illness based on the symptoms alone. Lack of NBS causes differential diagnostic challenges for physicians and delayed diagnosis of CF. We present a case of a two-year-old girl who was transferred to our hospital as a suspected Covid-19 patient with one week history of fever and coughing in March 2020. As Covid-19 was excluded, the severity of the clinical picture pointed towards an acute exacerbation of an underlying chronic condition. Her symptoms such as tachypnea, wheezing, lung crackles, hepatomegaly and clubbing of the fingers were all consistent with undiagnosed CF. In the end, sweat chloride level and genetic test verified the diagnosis. This case emphasizes the need of NBS in Hungary.

Keywords: Covid-19, cystic fibrosis, newborn screening

Introduction 
A cluster of cases of pneumonia were reported in Wuhan, China in December 2019. In January 2020 the genetic sequence of the novel corona virus was detected and in March the World Health Organization (WHO) characterized Covid-19 as a pandemic. Heim Pál Children's Hospital was assigned to hospitalize suspected or verified SARS-CoV-2 infected children in Central Hungary on $21^{\text {st }}$ March.

Case

A two-year-old girl was admitted to our hospital with a suspected diagnosis of SARS-CoV-2 pneumonia in March 2020. She presented in infancy with chronic cough, frequent respiratory illnesses, and failure to thrive $\left(\mathrm{BMI} 3^{\text {rd }}\right.$ percentile, $\mathrm{Z}$ score $\left.=-1,99\right)$.

In March 2020 she was admitted to the local hospital, in Eastern Hungary with fever, difficulty of breathing and one week history of coughing. Due to her respiratory symptoms a SARS-CoV-2 PCR test was carried out on the $7^{\text {th }}$ day of her illness. The result of the PCR test was unclear therefore she was transferred to our hospital. On arrival tachypnea, wheezing, lung crackles, hepatomegaly, clubbing of the fingers were found during the physical examination. It was also noticed that her weight was under the $3^{\text {rd }}$ percentile. Her saturation was $95 \%$ on $3 \mathrm{l} / \mathrm{min}$ oxygen flow via the nebulizing mask. Laboratory evaluation showed high white blood cell count with neutrophilia. Shortly after admission her work of breathing significantly increased, therefore high flow nasal cannula (HFNC) oxygen therapy was implemented. Despite the frequent use of bronchodilators and steroids wheezing did not improve. On the $10^{\text {th }}$ day of her illness nasopharyngeal swab for SARS-CoV-2 was reported to be positive by our hospital.

The result was a surprise as the case did not fulfill the environmental criteria of Covid-19 infection. First of all, the girl came from the rural part of Eastern Hungary where the number of confirmed Covid-19 cases was extremely low, and second of all, no one in the family was confirmed to be positive either. In addition to that, the severity of symptoms and her past medical history brought up the possibility of an undiagnosed underlying chronic condition. At that time, no false positive SARS-CoV-2 PCR result was reported in the literature, therefore we repeated the tests. Further testing, real time PCR nasopharyngeal swab tests and serology tests were all found to be negative therefore we excluded the diagnosis of Covid-19. According to our recent knowledge, above 34 replication cycles no positive viral culture is obtained. (1) Our explanation for the initial positive test could have come from the fact that our laboratory repeated the PCR replication above 34 cycles and nonspecific signals were misinterpreted positive.

On day 10 after admission, she was transferred to the Pediatric Intensive Care unit for invasive ventilation due to further respiratory distress on HFNC. All together, she required 10 days of mechanical ventilation. Due to the worsening clinical picture, high resolution computed tomography (HRCT) was performed, which revealed bronchial wall thickening, mucus plugging and bronchiectasis consistent with CF (Figure). Pseudomonas aeruginosa and methicillin-sensitive Staphylococcus aureus (MSSA) was isolated from sputum, therefore piperacillin-tazobactam $(100 \mathrm{mg} / \mathrm{kg} /$ piperacillin four times a day) and aminoglycoside $(20 \mathrm{mg} / \mathrm{kg} / \mathrm{day}$ once a day) were applied. After extubation, she needed further 10 days of non-invasive ventilation before she was finally stepped down to the General Pediatric ward.

Later on sweat chloride test $(112 \mathrm{mmol} / \mathrm{l})$ confirmed the diagnosis of cystic fibrosis $(\mathrm{CF})$, and a genetic test revealed a F508 del and G542X mutation. The patient was started on regular pancreatic enzyme replacement therapy, fat-soluble vitamins and nebulised colistimethate sodium. She was also assessed by multidisciplinary $\mathrm{CF}$ team and was started on regular physiotherapy. The CF-specific therapy led to a better physical condition, but the consequences of the delayed diagnosis and treatment are unknown at this stage.

\section{Discussion}

The Covid-19 pandemic in Hungary was started in the beginning of March. Children are mostly reported to have milder symptoms or are asymptomatic. The cause of the milder form of the disease is hypothesized due to the high exposure of other viruses and the low expression of ACE2 receptors. (2)

In 2018 in Hungary, there was a total of 523 patients with CF (age at diagnosis 2.65 years) out of 9.7 million inhabitants. Unfortunately the number of phenotyping, the average FEV1\% and the BMI z-score lag far 
behind the European average and the age of time at lung transplantation is lower.

In Europe there are many different CF NBS protocols. All current protocols rely on immunoreactive tripsinogen (IRT) at birth, intermediate tiers consists of CFTR mutation analysis or an IRT resampling, and as a last step a sweat chloride test is made to distinguish between NBS false and true positive cases. (3) In Hungary national NBS program is not available yet. However, the protocol of the NBS is elaborated for years. (4) This case underlines the need of a national NBS program of CF in Hungary.

Early diagnosis and CF specific therapy from the early stage may protect lungs from serious damages and disease progression. It is well known that countries where NBS was introduced, the median age at the diagnosis decreased; for example in England from 2,4 years to 3 weeks of age. Mak et al. compared different provinces in Canada at the same time where NBS was already introduced and where it was not applied yet. (5) With the introduction of NBS, CF was diagnosed earlier, pancreatic insufficiency was less common, mean z-scores for weight-for-age and height-for-age was higher. The frequency of hospital admission was reduced and there was a lower prevalence of colonization with Pseudomonas aeruginosa and Staphylococcus aureus. Lung infections were treated earlier so they did not cause irreversible lung damage.

\section{Message}

Our experience suggests that the lack of national NBS program of CF leads to delayed diagnosis in Hungary. Introducing NBS of CF may decrease the age at the time of diagnosis that could lead to a better quality of life and clinical state of the patients. In the meantime, clinicians in Hungary should always consider CF as part of their differential diagnosis at cases with recurrent respiratory infections and failure to thrive.

\section{Acknowledgement}

The authors would like to express thanks to Katalin Márai MD, for her clinical advices in the diagnosis and intensive care management of this case.

Figure: Chest CT: Peribronchial thickening, mucus plugging and severe bronchiectasis in the lungs

Conflict of interest: The authors declare they have no conflict of interest.

\section{References}

1. La Scola B, Le Bideau M, Andreani J et al. Viral RNA load as determined by cell culture as a management tool for discharge of SARS-CoV-2 patients from infectious diseases wards. Eur J Clin Micorbiol Infect Dis 2020; 39:1059-1061.

2. Brodin P. Why is Covid-19 so mild in children? Acta Paediatrica 2020; 109:1082-1083.

3. Castellani C, W.Southern K, Brownlee K et al. European best practice guidelines for cystic fibrosis neonatal screening. Journal of Cystic Fibrosis 8 2009; 153-173.

4. Kalmár T, Nagy D, Újhely R et al. A cystás fibrosis újszülöttkori szürése és az azt követô teendôk. Mucoviscidosis Hungarica 2018; 4(2): 229-245.

5. Mak DYF, Sykes J, Stephenson AL et al. The benefits of newborn screening for cystic fibrosis: The Canadian experience. Journal of Cystic Fibrosis 2016; 15 302-308. 


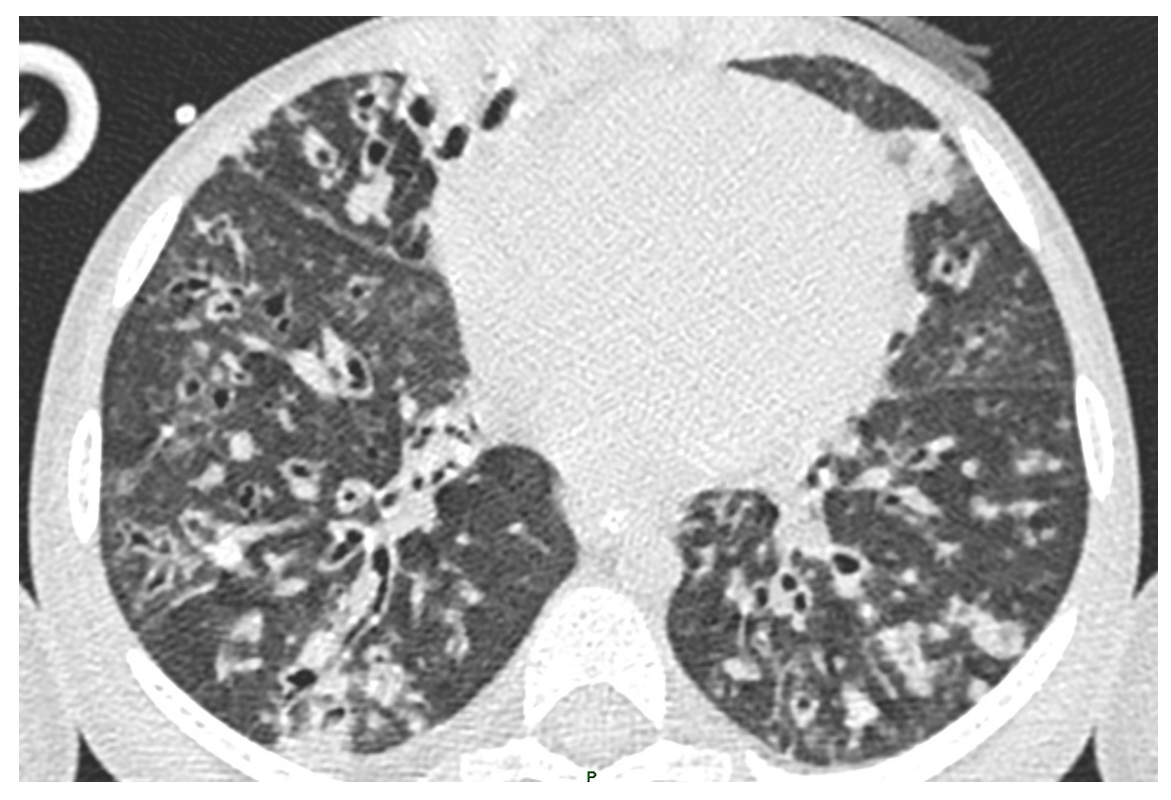

